\title{
The Loading Characteristics of Bulk Coal in the Middle Trough and Its Influence on Rigid Body Parts
}

\author{
Peilin Zhang 1,2 - Bo Li1,2 - Xuewen Wang 1,2,* - Chaoyang Liu ${ }^{1,2}$ - Wenjie Bi1,2 - Haozhou Ma1,2 \\ ${ }^{1}$ Shanxi Key Laboratory of Fully Mechanized Coal Mining Equipment, China \\ 2 Taiyuan University of Technology, College of Mechanical and Vehicle Engineering, China
}

\begin{abstract}
The working reliability of a scraper conveyor is related to the bulk coal load characteristics and the interaction between rigid body parts and bulk coal. In the existing relevant research, a load of coal on rigid body parts is equivalent to constant central acting on some points, ignoring time-varying and uneven distribution of the load and new load generated by the interaction, which results in some load characteristics and related faults being obscured. In this paper, the rigid-discrete coupling simulation model of scraper conveyor is established based on the discrete element method and the multi-body dynamic method, and the overall compressive force gradient distribution of bulk coal in the middle trough, the violent interaction between bulk coal and rigid body parts, and the clamping stagnation of scrapers are studied. The results show that the bulk coal compressive force has an obvious distribution gradient in the chute, and in the chute between two scrapers, the bulk compressive force in the first half is about $19 \%$ of that in the second half in the $y$-direction. The coal particles stuck between the scrapers, the vertical chainrings, and the middle plates violently interact with the rigid body parts, and the coal particles average compressive force is 59 times that of other coal particles. The scraper influenced by bulk coal is easily stuck at the connection of two chutes, and the tension of the chain before the scraper increases sharply, and the maximum tension of the chainrings is about three times that of the maximum contact force between the scraper and the chute.
\end{abstract}

Keywords: scraper conveyor, discrete element method, multi-body dynamics, compressive force distribution gradient, violent interaction

\begin{abstract}
Highlights
- The rigid-discrete coupling model of a scraper conveyor can simulate the interaction between the bulk coal and the rigid parts.

- The compressive force distribution of coal in the middle trough has an obvious gradient, and the load characteristics of the rigid body parts applied by bulk coal can be analysed through the bulk coal compressive force distribution.

- Coal particles are easily stuck between scraper, vertical chainring and middle plate, which affects the force and movement of the scraper and the chain as well as the wear of middle plate.

- It is easy for the scraper to get stuck at the connection of two chutes, which causes the tension of the chain to increase sharply.
\end{abstract}

\section{INTRODUCTION}

A scraper conveyor in a fully mechanized mining face is the coal transport equipment, together with shearer and hydraulic support, that comprises a fully mechanized mining face [1] and [2]. The reliability and service life of scraper conveyor have a great influence on the coal mining efficiency and the economic efficiency of coal mining. The working environment of a scraper conveyor is very harsh, which makes it prone to failure. Once a fault occurs, the normal excavation work will be interrupted, and the underground maintenance is very difficult, which wastes a great deal of manpower, material, and financial resources. Therefore, the study of scraper conveyor failure mechanism, efforts to improve its work reliability, and extending the working life are the long-standing pursuits of many researchers.

There are primarily three failure modes for the relevant parts of scraper conveyor: the chain break, the wear of middle plate, and of sprocket drum. Researchers have mainly studied the motion and the force characteristics of related parts, the wear mechanism, and wear resistance measures of the middle plate and sprocket drum. Based on the finite element concept, the physical and mathematical models of scraper conveyor are established to study dynamic characteristics of the chain drive system [3]. The polygon effect of the chain drive has an important impact on the dynamic performance of the scraper conveyor [4] and [5]. The load on the scraper and chain is uneven and unpredictable, and the load under different working conditions and the load change at any point affect the dynamic characteristics of the whole drive system [6] to [9]. The contact force change characteristics between the chain ring, scraper and sprocket, flat ring and vertical ring, as well as the stress and strain of these parts, are studied [10] and [11]. The chain tension also affects the motion and force characteristics of the chain drive system, and real-time monitoring and adjusting the tension is also one significant research direction [12] and [13]. The driving force of the scraper conveyor can affect the dynamic load of the chain drive. Optimizing the control algorithm of the driving system can improve the dynamic behaviour of the scraper conveyor [14] 
and [15]. The dynamic load characteristics, the wear and the wear resistance improvement of sprocket drum are critical research directions [16] to [18]. Many studies have been done on the medium plate wear mechanism, the factors affecting the wear and the improvement of the wear resistance [19] to [21]. Most of these studies assume the load imposed by coal bulk to the relevant parts as a constant value, ignoring the time-varying, uneven distribution of coal bulk load and the possible new load generated by the interaction of coal bulk and parts, resulting in the concealment of some force characteristics and failure mechanism of the relevant parts.

The discrete element method (DEM) is a numerical calculation method proposed by Cundall et al. to simulate bulk materials, which has been widely used in studies related to bulk materials [22] and [23]. Wang et al. studied the size distribution, velocity distribution, and transport efficiency of coal particles in the middle trough with DEM, but the rigid body parts in their model could only move along a straight line [24] and [25]. DEM provides a method to simulate bulk material, but the geometric model in DEM commercial software EDEM can only realize simple motion, so it is necessary to combine it with other dynamic software to study the mechanical system with complex motion.

Multi-body dynamics (MBD) is a subject that studies the motion rules of multi-body systems; it can be used to establish models to analyse the force and motion rules for complex multi-body systems [26] and [27]. In the related studies on scraper conveyors, MBD is mostly used to study the motion and force characteristics of the chain drive system [11] and [28]. MBD provides a powerful tool for studying the force characteristics among geometries in a multi-body system.

This paper focuses on the overall compressive force distribution gradient of coal bulk in the middle trough, the violent interaction between coal bulk and rigid body parts, and the influence of bulk on rigid body parts, especially on the scraper and chain. The overall compressive force gradient distribution reveals the load distribution characteristics of bulk coal, the violent interaction between bulk coal and rigid parts produces new loads, and the influence of bulk coal on rigid parts reveals the principle of some faults.

This research is organized as follows. In Section 1 , the coupling model is introduced and its reliability is verified; in Section 2, the simulation results with discussions are presented; in Section 3, the conclusions are given.

\section{RESEARCH METHOD}

\subsection{Scraper Conveyor Model}

The type of scraper conveyor in this study is SGZ880/800, and its specific parameters are shown in Table 1. The complete virtual prototype of scraper conveyor is shown in Fig. 1a, and the simplified model of scraper conveyor in this study is shown in Fig. 1b. The geometric model is modelled with Siemens Unigraphics NX 10.0 (UG 10.0). The longest scraper conveyor used in longwall system can reach to $500 \mathrm{~m}$, and the number of links in the chain is hundreds of thousands [6]. If a complete scraper conveyor model is adopted to establish the simulation model, the number of rigid bodies and kinematic pairs will be greatly increased, and the number of coal particles participating in the simulation will also be increased dozens of times, which can cause simulation on an ordinary computer to be time-consuming or not feasible at all. Therefore, the simulation

Table 1. Specific parameters of the scraper conveyor

\begin{tabular}{lccc}
\hline Type & $\begin{array}{c}\text { Power } \\
{[\mathrm{kW}]}\end{array}$ & $\begin{array}{c}\text { Chain } d \times t \\
{[\mathrm{~mm} \times \mathrm{mm}]}\end{array}$ & $\begin{array}{c}\text { Chute } L \times B \times H \\
{[\mathrm{~mm} \times \mathrm{mm} \times \mathrm{mm}]}\end{array}$ \\
\hline SGZ880/800 & $2 \times 400$ & $34 \times 126$ & $1500 \times 880 \times 330$ \\
\hline
\end{tabular}
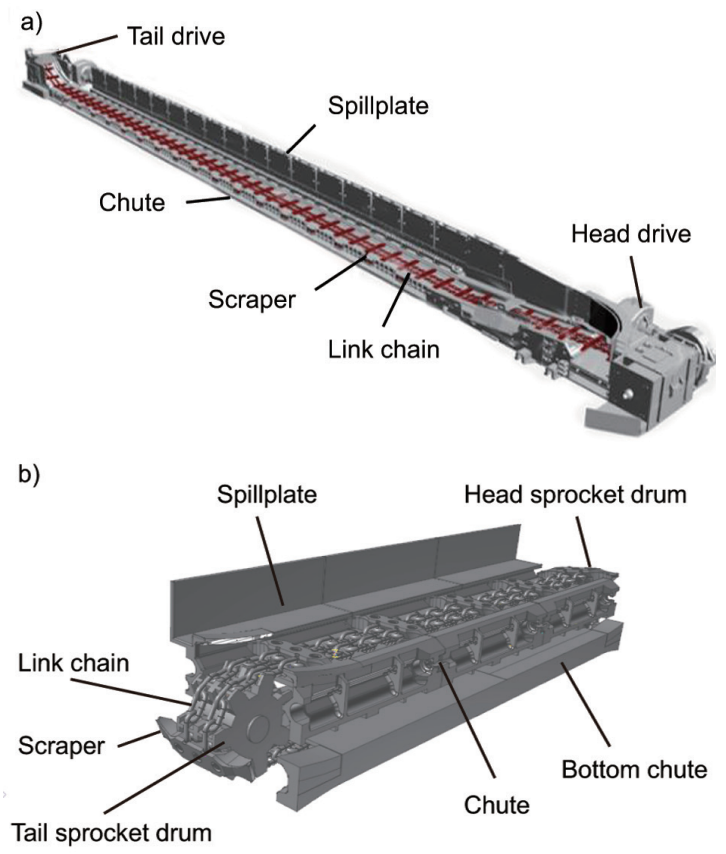

Fig. 1. Virtual prototype of scraper conveyor; a) the complete; and b) the simplified 
model is simplified as necessary. The simplified model eliminates the gearboxes, drive motors, and hydrodynamic coupling in the head and tail drives, and only the head and tail sprocket drums, three chutes, scrapers, link chains, and so on are retained. At the same time, adding a bottom chute, scrapers and chains return to tail from the head through the bottom chute. In the simplified model, the scraper and chain move smoothly in the middle trough driven by the sprockets, which meets the research requirements.

\subsection{Simulation Model and Its Parameters}

\subsubsection{The Coupled Model}

The process of conveying bulk coal by scraper conveyor involves bulk coal and rigid parts of the scraper conveyor (all parts of the scraper conveyor in this research are rigid bodies). DEM can simulate bulk coal, but the discrete element software cannot simulate the complex motion of rigid body parts, so multi-body dynamics software can be used to simulate the complex motion. Therefore, discrete element software and multi-body dynamics software are used to simulate the transport of coal bulk in the scraper conveyor together.

The coupling model is established by using multi-body dynamics software Recursive Dynamic (RecurDyn) and discrete element software EDEM. The simplified virtual prototype model established in UG is imported into RecurDyn, where the dynamics model is established, and then the virtual prototype is exported from RecurDyn to a file in WALL format, and then the file is imported into EDEM as the geometric model to establish the discrete element model. In the process of coupling simulation, the two models run simultaneously, and the calculated data are shared through the WALL file in real time. EDEM calculates the forces and motions of bulk coal, Recurdyn calculates the forces and motions of rigid body parts, and the computational results of the two models are shared in real time to be used as the boundary condition of the next time step, as shown in Fig. 2. This is how the coupling model simulates the interaction between bulk and rigid parts.

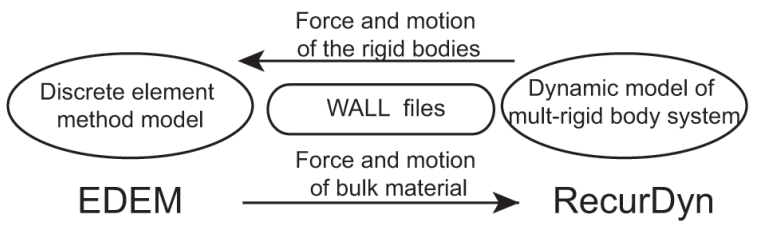

Fig. 2. Schematic diagram of coupling model

\subsubsection{Discrete Element Model}

\section{(1) Contact model}

The contact model defines the calculation method of forces between particles, particle and geometry. The simulation model needs to define the contact model between particles and between particle and geometry, respectively. Both contact models select the HertzMindlin (no slip) model, which is the basic contact model in EDEM software, which can accurately and efficiently calculate the forces. In the model, normal force is based on the Hertz contact theory [29], and the tangential force is based on the research results of Mindlin-Deresiewicz [30]. Let two spherical particles with radius $R_{1}$ and $R_{2}$ make elastic contact, and four forces are generated between the two spheres: normal force, normal damping force, tangential force and tangential damping force.

Normal force $F_{n}$ between particles can be obtained by Eq. (1).

$$
F_{n}=\frac{4}{3} E^{*}\left(R^{*}\right)^{1 / 2} \alpha^{3 / 2}
$$

where $E^{*}[\mathrm{~Pa}], R^{*}[\mathrm{~m}]$ and $\alpha[\mathrm{m}]$ are equivalent Young's modulus, equivalent particle radius, and normal overlap, respectively.

The normal damping force $F_{n}^{d}$ can be obtained by Eq. (2).

$$
F_{n}^{d}=-2 \sqrt{\frac{5}{6}} \beta \sqrt{S_{n} m^{*}} v_{n}^{r e l},
$$

where $\beta$ is a coefficient associated with the coefficient of restitution, $S_{n}\left[\mathrm{Nm}^{-1}\right], m^{*}[\mathrm{~kg}]$ and $v_{n}^{\text {rel }}\left[\mathrm{ms}^{-1}\right]$ are normal stiffness, equivalent mass and normal components of relative velocity, respectively.

Tangential force $F_{t}$ can be obtained by Eq. (3).

$$
F_{t}=-S_{t} \delta,
$$

where $S_{t}\left[\mathrm{Nm}^{-1}\right]$ and $\delta[\mathrm{m}]$ are tangential stiffness and tangential overlap, respectively.

Tangential damping force $F_{t}^{d}$ can be obtained by Eq. (4).

$$
F_{t}^{d}=-2 \sqrt{\frac{5}{6}} \beta \sqrt{S_{t} m^{*}} v_{t}^{r e l},
$$

where $\beta$ is a coefficient associated with the coefficient of restitution, $S_{t}\left[\mathrm{Nm}^{-1}\right]$ and $v_{t}^{\text {rel }}\left[\mathrm{ms}^{-1}\right]$ are tangential stiffness and the tangential component of the relative velocity, respectively.

Please refer to the literature for the calculation of specific parameters in the above formulas [31]. 
(2) Particle model and particle factory

The irregular shape of coal particles can be roughly classified into three categories: flat, block, and cone. In EDEM, coal particle model is composed of pellets. A new particle can be formed by defining the radius and relative position of each pellet in the coordinate system. The maximum length of the coal particle model in three coordinate directions is used to represent the particle size of coal particles. Fig. 3 shows the shape of the coal particle model established in EDEM, a) is block, b) is flat and c) is cone. Coal particles are produced by the particle factory above the middle trough near the tail sprocket. The particle factory is set as a cube area that the length, width, and height are $850 \mathrm{~mm}, 1000 \mathrm{~mm}$, and $200 \mathrm{~mm}$, respectively. The particle factory can produce coal particles at a certain rate and define the initial state of coal particle, and its position is fixed.

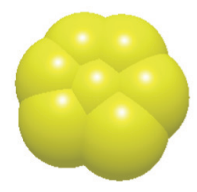

a)

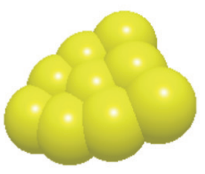

b)

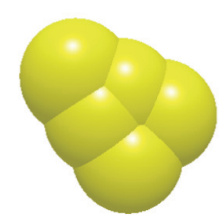

c)
Fig. 3. The shape of coal particles; a) block; b) flat; and c) cone

\section{(3) Related parameters}

The parameters in the discrete element model mainly involve the intrinsic parameters of bulk coal and rigid materials and the contact parameters of the contact model. The parameters in the simulation are from the existing research results of this research group, and the specific parameters are shown in Tables 2 and 3 [32].

Table 2. The intrinsic parameters of bulk and rigid materials

\begin{tabular}{lccc}
\hline Material & Shear modulus $[\mathrm{GPa}]$ & Poisson's ratio & Density $\left[\mathrm{kg} \cdot \mathrm{m}^{-3}\right]$ \\
\hline Coal & 0.47 & 0.3 & 1229 \\
\hline Steel & 80 & 0.3 & 7850 \\
\hline
\end{tabular}

Table 3. Recovery coefficient and friction coefficient

\begin{tabular}{lcc}
\hline \multirow{2}{*}{ Recovery coefficient } & Coal - coal & 0.64 \\
\cline { 2 - 3 } & Coal - steel & 0.65 \\
\hline \multirow{2}{*}{ Static friction } & Coal - coal & 0.329 \\
\cline { 2 - 3 } & Coal - steel & 0.46 \\
\hline \multirow{2}{*}{ Coefficient of kinetic friction } & Coal - coal & 0.036 \\
\cline { 2 - 3 } & Coal - steel & 0.032 \\
\hline
\end{tabular}

\subsubsection{Dynamic Model}

RecurDyn software adopts the motion equation theory of relative coordinate systems and the complete recursion algorithm, which is very suitable for solving large-scale multi-body system dynamics problems. And compared with other dynamic software, RecurDyn can truly, efficiently and stably handle contact collision problem. The scraper chain consists of a large number of chain links and the dynamic model is very complex, and RecurDyn can effectively improve the calculation speed. The interaction between the chainrings, the chainring and the chain wheel and so on is expressed by contact pair, which can effectively simulate the movement of scraper conveyor rigid body parts.

In the dynamic model of scraper conveyor, the kinematic pairs of rigid body parts are shown in Fig. 4. The action relationship between parts in the dotted frame in the figure is represented by contact pair, including vertical chain and flat chain, chain and scraper, chain and sprocket, and so on. The head and tail sprockets are fixedly connected to the rack (ground) through the revolute pair; the chute is fixedly connected to the ground with a fixed pair. The driving force of sprocket is defined by the revolute pair; two sprockets drive the chain and scrapers simultaneously. The head sprocket drives the chain and scrapers in the forward stroke, and the tail sprocket drives in the return stroke.

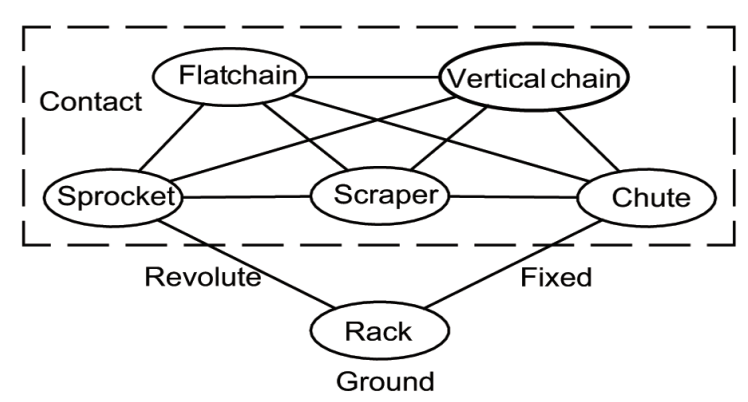

Fig. 4. The kinematic pairs between rigid body parts

\subsection{Verification Test of Discrete Element Model}

To ensure the reliability of simulation results, it is necessary to verify that the coupling model can truly simulate the coal transportation process. If the verification test is carried out directly on the scraper conveyor corresponding to the simulation model, the requirement for the test equipment is high, and the cost is substantial. Since the discrete element model and the multi-body dynamics model that constitutes 
the coupling model are independent of each other, it is only necessary to verify that the two models meet the research requirements. Discrete element model is the core of the coupling model, the multi-body dynamics model of scraper conveyor can realize the complex motion of rigid body parts and meets these research requirements. so the emphasis is to verify the reliability of the discrete element model.

The core parts of a discrete element model are the contact model, the particle model, and the relevant parameters of bulk material and rigid body, etc. Moreover, the geometric model is not very important. As long as these models are appropriate and key parameters are reliable; then the discrete element model can truly simulate bulk coal. The validation test is to verify the reliability of these models and parameters. The idea of verification testing is using the same contact model, particle model, and related parameters of design simulation and check test on a turntable testbed to prove that the simulation model can accurately simulate the bulk coal by comparing the results of simulation and test.

The check test was carried out on the turntable testbed in Fig. 5a. The turntable can rotate around its central axis, and the sample above the turntable is fixed on the rack by a three-dimensional force sensor that can measure the force exerted on the sample by the coal. The bottom surface of the sample is $8 \mathrm{~mm}$ away from the surface of the turntable, so there is no friction between the sample and the turntable, and the coal particles are not easily stuck between them. Lay $1 \mathrm{~kg}$ bulk coal in the turntable which rotates counter clockwise for 1 cycle at $\pi / 2 \mathrm{rad} / \mathrm{s}$. In the test, the coal particles with a size of $2 \mathrm{~mm}$ to $4 \mathrm{~mm}$ are screened. Furthermore, the particle sizes are randomly distributed between $2 \mathrm{~mm}$ to $4 \mathrm{~mm}$ in simulation. Rotating with the turntable, the bulk coal exerts thrust on the sample in the circumferential tangential direction, and the sample will leave a groove on the bulk coal. The thrust and the groove section curve cut by the plane perpendicular to the turntable upper surface and across the turntable centre are selected as the test results, which represent the force of bulk coal and bulk coal fluidity, respectively. To avoid contingency, three positions are selected to measure the groove section curves. If the initial position of the sample is $0^{\circ}$ and one revolution of the turntable is $360^{\circ}$, the groove section curves at the positions of $90^{\circ}, 180^{\circ}$, and $270^{\circ}$ are respectively taken. Fig. $5 \mathrm{~b}$ is the schematic diagram of the simulation, and the geometric model is composed of the turntable and sample. The thrust in the simulation is obtained from the WALL file of the sample in RecurDyn. By establishing a two-dimensional coordinate system, coordinate values of the groove section curves at some equidistant points were measured, and the groove section curves can be obtained through curve fitting. Take the intersection point of the vertical centreline of the sample and the plane of the turntable upper-end face as the coordinate origin, take the radial direction of the turntable at the origin as the $\mathrm{X}$-axis, and the vertical centreline of the sample as the Y-axis, and establish a two-dimensional coordinate system, as shown in Fig. 5b. Take a point at $8 \mathrm{~mm}$ intervals along both sides of the $\mathrm{X}$-axis, measure the $\mathrm{y}$-coordinate values of the groove section curve at these points, and measure 11 points of data together with the origin, and fit the groove section curve from these data points. The groove section curves in simulation and test are obtained by taking points, measuring data and fitting curves.

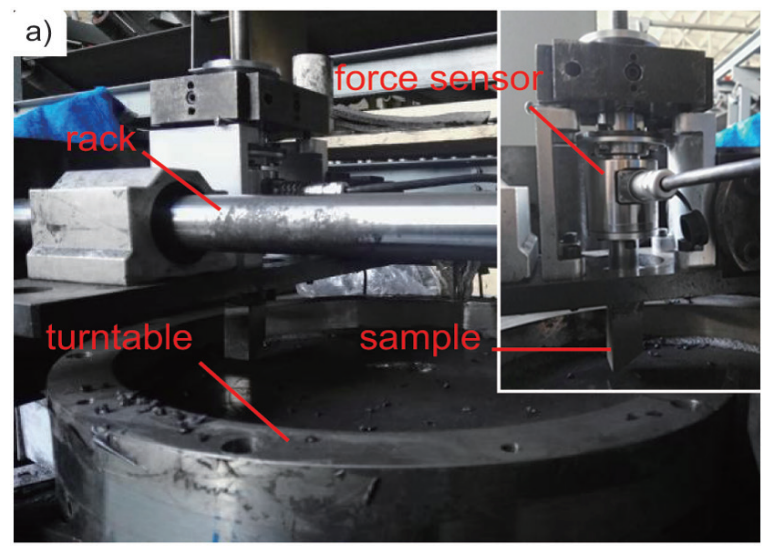

b)

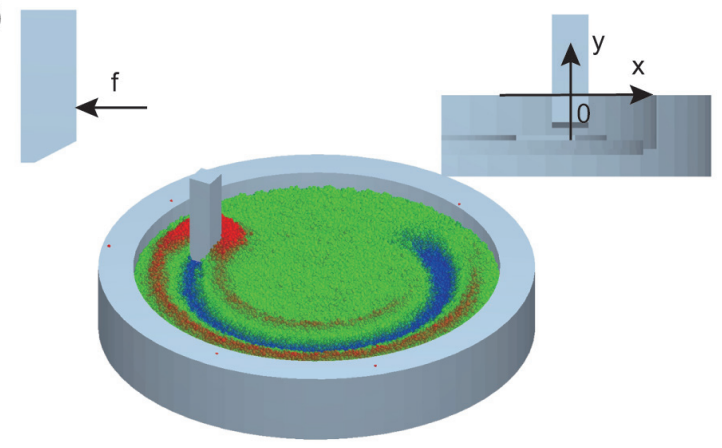

Fig. 5. Verification test equipment and simulation diagram; a) verification test equipment; and b) simulation diagram

Fig. 6a is the diagram of the physical test, and Fig. $6 \mathrm{~b}$ is the shape of the groove section at the $90^{\circ}$ position in the simulation. Fig. $6 \mathrm{c}$ is the circumferential tangential thrust curve of the sample exerted by bulk coal. The blue curve is the simulation curve, and the red curve is the test curve. There are some mutation 
a)
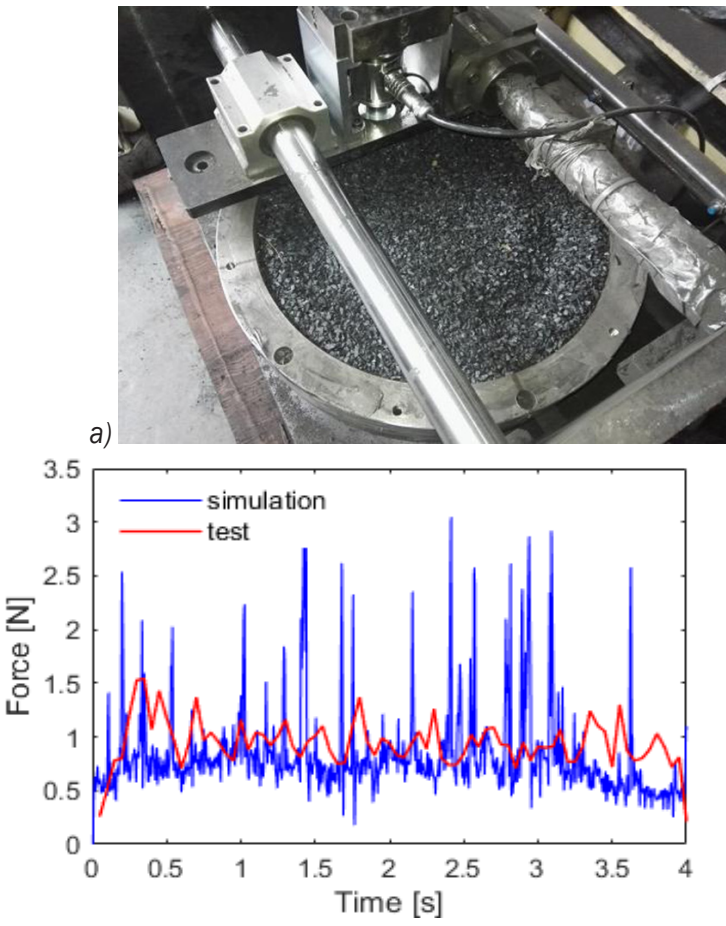

c)

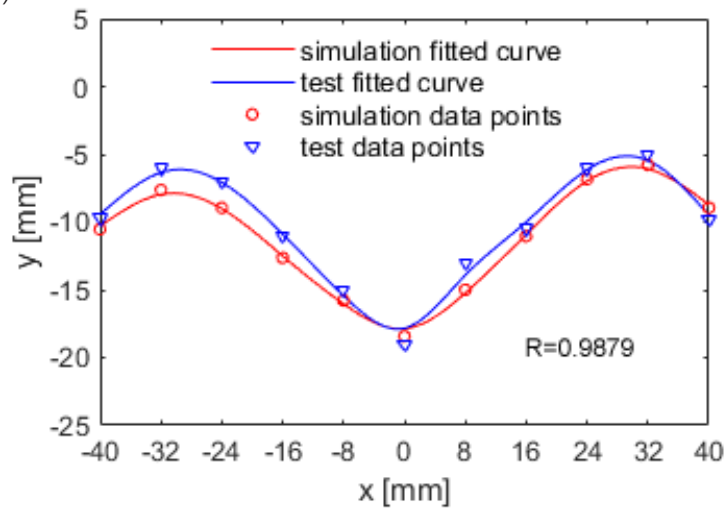

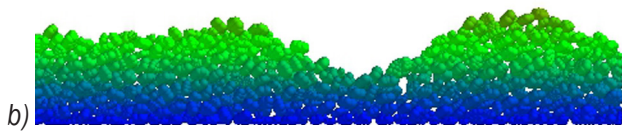

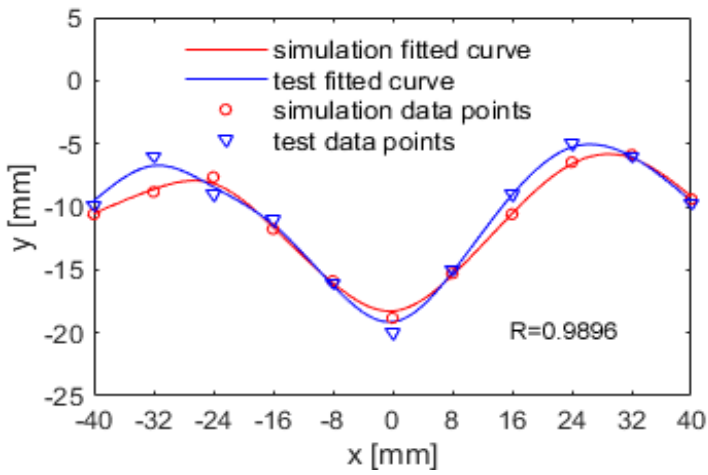

d)

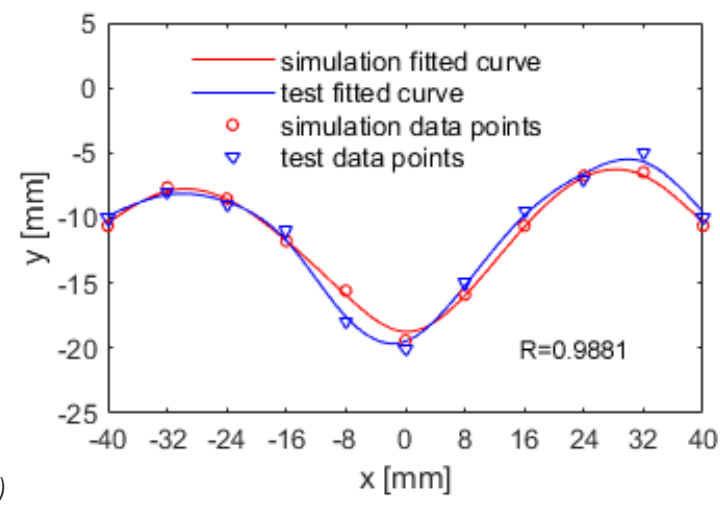

Fig. 6. Simulation and test results: a) test physical diagram; b) the shape of the groove section at $90^{\circ}$ in simulation; c) the thrust curve; d) $90^{\circ}$ groove section curve; e) $180^{\circ}$ groove section curve; f) $270^{\circ}$ groove section curve

points in the blue curve and the mutation generated by the extrusion between the particles flowing under the sample and the sample. In the test, due to the low sampling frequency of the sensor, the sudden change of force cannot be captured or presented, and the force curve reflects the thrust without mutation and corresponds to the relatively smooth part in the simulation curve. Therefore, the method of average value is used to compare the closeness of the two curves. The average value of the red curve is $0.94 \mathrm{~N}$, the average value of the blue curve is $0.82 \mathrm{~N}$, and the ratio of the simulation value to the test value is $87 \%$. The bulk material force in simulation is close to the real working condition. Fig. $6 \mathrm{~d}$ to $\mathrm{f}$ are groove section curves at $90^{\circ}, 180^{\circ}, 270^{\circ}$, respectively. The small red circles and blue triangles in the figures are data points of groove section curves measured respectively in simulation and test. The smooth spline fitting tool in MATLAB is used to fit these data points to get groove contour curves. All of these fit curves have $R^{2}$ of 0.9901 . The correlation coefficients $R$ of the two fitted curves in simulation and test at the positions of $90^{\circ}, 180^{\circ}$ and $270^{\circ}$ are $0.9896,0.9879$ and 0.9881 , respectively, which indicates that the fluidity of bulk coal simulated by the simulation model is very similar to that in the test. The results of above comparisons indicate that the discrete element model can realistically simulate the bulk coal and meet the research requirements. 


\subsection{The Simulation}

The load distribution of bulk coal is related to the bulk coal compressive force distribution. The force inside the bulk is transmitted through the compressive force. The greater the bulk coal compressive force is, the greater the load on rigid body parts is, and the greater the friction force applied to rigid body parts is. Firstly, the compressive force distribution gradient of bulk coal in the middle trough is analysed to obtain a general understanding of the bulk coal load distribution. Secondly, the interaction between bulk coal and rigid body parts generates new loads, and the large load generated by violent action significantly affects the normal work of scraper conveyor. Find the coal particles that violently act with rigid body parts, and then analyse the violent action process. Finally, some possible faults of rigid parts are analysed.

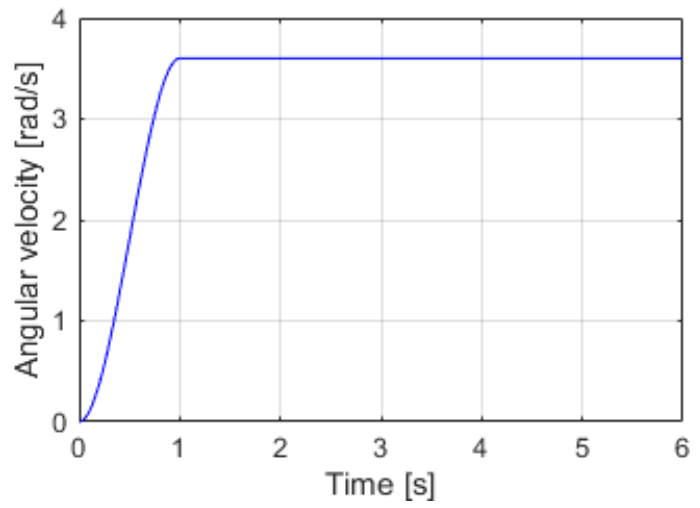

Fig. 7. The rotation speed of sprockets

The bulk coal in the simulation is composed of three shapes of particles. The particle factory produces $220 \mathrm{~kg}$ bulk coal every second, and the mass of each shape particle accounts for $1 / 3$ of the total mass. Particle size is selected as $40 \mathrm{~mm}$ for three shapes of particles and the total particle quantity is unlimited. Coal particles fall to the middle trough at a certain initial velocity, and the components of the velocity are $v_{x}=-0.2 \mathrm{~m} / \mathrm{s}, v_{\mathrm{y}}=0.4 \mathrm{~m} / \mathrm{s}, \mathrm{v}_{\mathrm{z}}=-1 \mathrm{~m} / \mathrm{s}$. The initial tension of the scraper chain can be set by adjusting the distance of two sprockets, and the initial tension is about $20,000 \mathrm{~N}$. The scraper conveyor is driven by the sprockets at the same time as same rotation speed, the rotation speed is shown in Fig. 7, and the total simulation time is $6 \mathrm{~s}$. The process of producing coal at the tail end of the scraper conveyor and transporting it to the head end at a speed of about $1.02 \mathrm{~m} / \mathrm{s}$ is simulated.

\section{RESULTS AND DISCUSSION}

\subsection{Compressive Force Distribution Gradient of Bulk Coal in Middle Trough}

The total simulation time is $6 \mathrm{~s}$, the whole middle trough is full of bulk coal at $3.3 \mathrm{~s}$, and the transport of bulk coal in the middle trough is relatively stable at $5 \mathrm{~s}$, so choose the time of $5 \mathrm{~s}$ to draw the bulk coal compressive force cloud diagram. Fig. 8a is the bulk coal compressive force cloud diagram cut by the plane perpendicular to the $\mathrm{x}$-axis. The plane perpendicular to the $\mathrm{x}$-axis cuts the middle trough along e-e line in Fig. 8c. And the e-e line is in the middle of the chute inner edge and chain, $375 \mathrm{~mm}$ from the spillplate edge. Arrow $\mathrm{V}$ indicates the motion direction of the scraper and chain. In the figure, the red bulk coal is mainly located in the chute, which is framed with black lines, while the bulk coal above the chute is mainly bluegreen. Therefore, the compressive force of bulk coal in the chute is significantly greater than that above the chute. Fig. $8 \mathrm{~b}$ is the bulk coal compressive force cloud diagram cut by the plane perpendicular to the z-axis. That plane cuts the middle trough along the $\mathrm{f}-\mathrm{f}$ line in Fig. 8c. The $\mathrm{f}-\mathrm{f}$ line is $120 \mathrm{~mm}$ away from the upper edge of chute, and the maximum compressive force in the cloud diagram increases to $45 \mathrm{~N}$. The area between the two scrapers in the chute middle is divided into six cubic sub-areas marked as A, B, C, D, E and F respectively, and the cross-section shape of the six cubic sub-areas is shown in Fig. 8b and c. In Fig. 8b, $\mathrm{A}, \mathrm{B}$ and $\mathrm{C}$ are mainly red, $\mathrm{D}, \mathrm{E}$ and $\mathrm{F}$ are mainly blue, and $\mathrm{B}$ is less red than $\mathrm{A}$ and $\mathrm{C}$, while $\mathrm{E}$ is more blue than $\mathrm{D}$ and $\mathrm{F}$. Therefore, in the $\mathrm{y}$-direction, the bulk coal compressive force in $\mathrm{A}, \mathrm{B}$ and $\mathrm{C}$ is higher than that in $\mathrm{D}, \mathrm{E}$ and $\mathrm{F}$, respectively, in the $\mathrm{x}$-direction, the bulk coal compressive force in $\mathrm{B}$ is lower than that in $\mathrm{A}$ and $\mathrm{C}$, and in $\mathrm{E}$ is lower than in $\mathrm{D}$ and $\mathrm{F}$. The average compressive force $\mathrm{F}$ of the bulk coal in the six areas at $5 \mathrm{~s}$ is shown in Table $4 . F_{D} / F_{A}=21 \%$, $F_{E} / F_{B}=16 \%, F_{F} / F_{C}=19 \%$, and the average value of the three ratios is $19 \% . F_{B} / F_{A}=79 \%, F_{B} / F_{C}=81 \%$, $F_{E} / F_{D}=59 \%, F_{E} / F_{F}=70 \%$, and the average value of the four ratios is $72 \%$. Therefore, in the area between two scrapers, in the y-direction, the bulk coal compressive force in the first half is about $19 \%$ of that in the second half, and in the x-direction, the bulk coal compressive force between the two chains is about $72 \%$ of that between the chain and the chute edge. Fig. 8c is the bulk coal compressive force cloud diagram cut by the plane perpendicular to the y-axis. The plane perpendicular to the $y$-axis cuts the middle trough along the g-g line in Fig. $8 \mathrm{~b}$. The g-g line is in the 
Time: $5 \mathrm{~s}$

a)

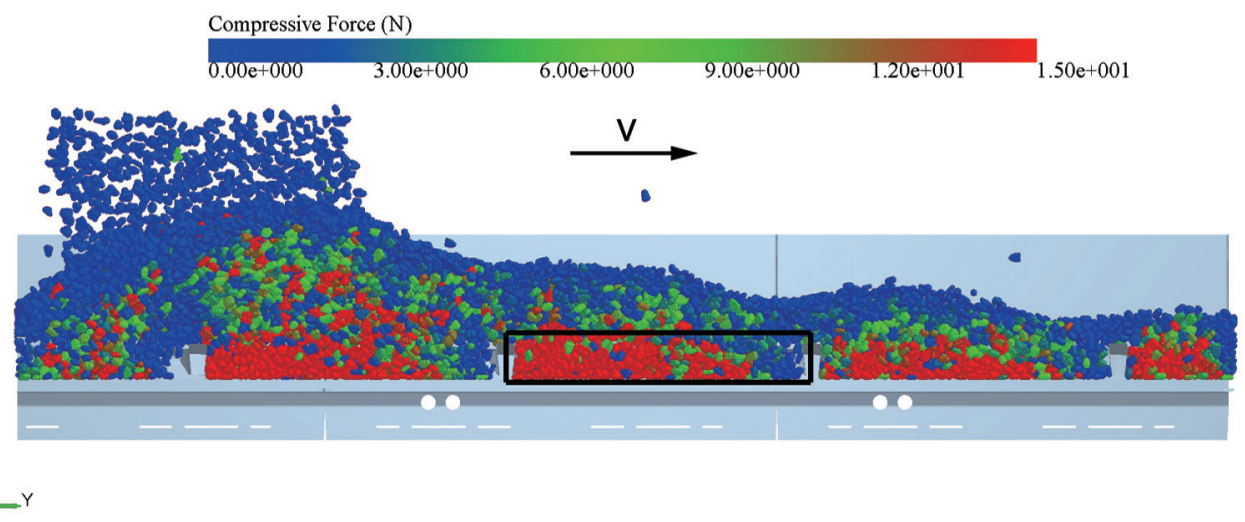

b)

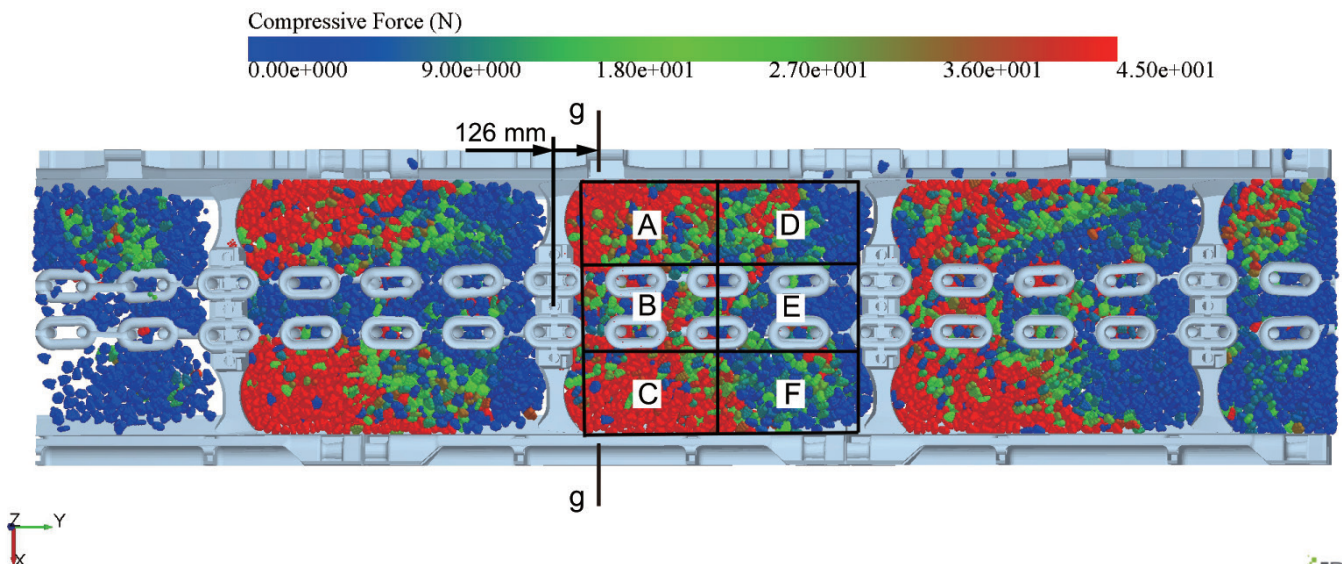

Time: $5 \mathrm{~s}$

c)

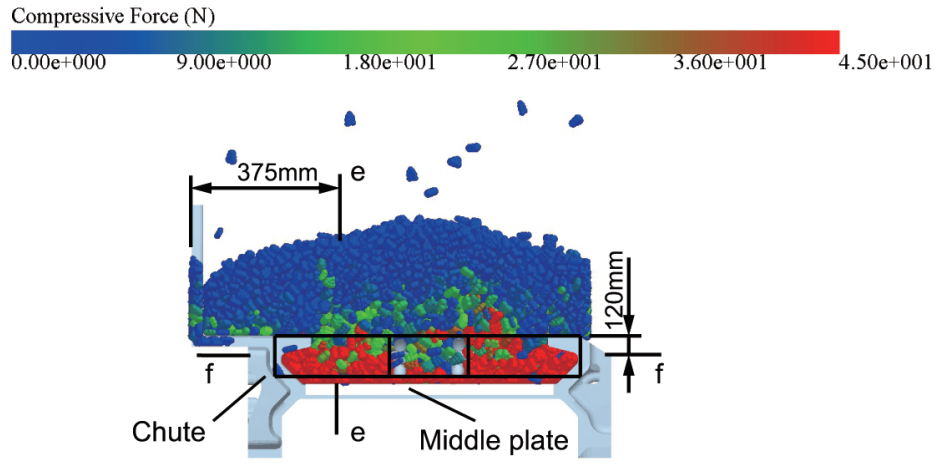

c)

Fig. 8. Bulk compressive force cloud diagram at $5 \mathrm{~s}$; a) cut by the plane perpendicular to the x-axis; b) cut by the plane perpendicular to the z-axis; c) cut by the plane perpendicular to the $y$-axis

centre of the chain-link adjacent to the scraper, 126 $\mathrm{mm}$ away from the centreline of the adjacent scraper, and the maximum value in the cloud diagram is $45 \mathrm{~N}$. This picture offers a new perspective.

Table 4. Bulk average compressive force in the 6 areas at $5 \mathrm{~s}$

\begin{tabular}{lcccccc}
\hline Area & A & B & C & D & E & F \\
\hline Force, $F[\mathrm{~N}]$ & 87 & 68 & 84 & 18 & 11 & 16 \\
\hline
\end{tabular}

The bulk coal compressive force in the chute is greater than that above chute. The bulk coal inside chute is squeezed by scrapers, middle plates, and chutes, and moves forward under the force. The bulk coal above chute moves forward under the friction force of bulk coal in the chute, so the compressive force is obviously smaller than that in the chute. The scraper pushes bulk coal move in the chute, the thrust 


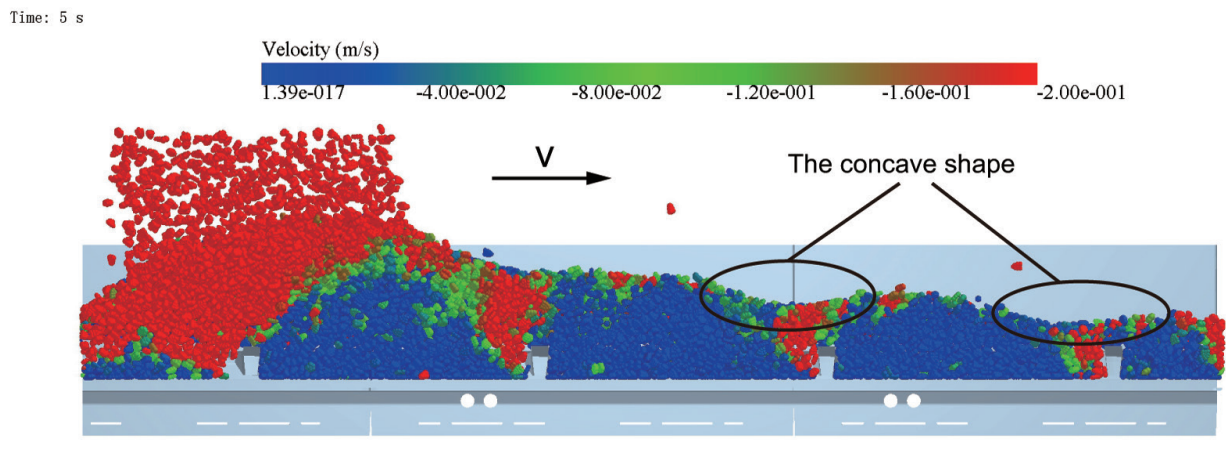

Fig. 9. Velocity cloud diagram of bulk coal in Z direction at $5 \mathrm{~s}$

is transmitted forward through the bulk, and the rear bulk coal pushes the front, so the rear bulk coal bears greater force. In addition, the middle plate and chute exert backward friction force on coal bulk, and the bulk coal near the former scraper moves relative to the backward scraper, which makes the bulk coal near the former scraper gradually loose, and the compressive force is reduced. while the force near the latter scraper becomes bigger due to aggregation. Fig. 9 shows the bulk coal $\mathrm{Z}$ component velocity cloud diagram at $5 \mathrm{~s}$ and arrow $\mathrm{V}$ indicates the motion direction of the scraper and chain. In the back of each scraper, bulk coal flows downward, while in the front of the scraper, bulk coal basically remains unchanged. This is because the bulk behind each scraper will become increasingly loosed, the bulk coal above will flow down to fill the gap left, the shape of the bulk will be concave down. The distance between chain and chute edge is larger than that between two chains. And the more obvious the effect of bulk coal extrusion is, the greater the compressive force is. Secondly, the influence of chain movement on the bulk coal between two chains weakens the bulk compressive force.

\subsection{The Violent Interaction between Bulk Coal and Rigid Body Parts}

Increase the maximum compressive force value to draw the bulk coal compressive force cloud diagram. The particles with extreme compressive force are all

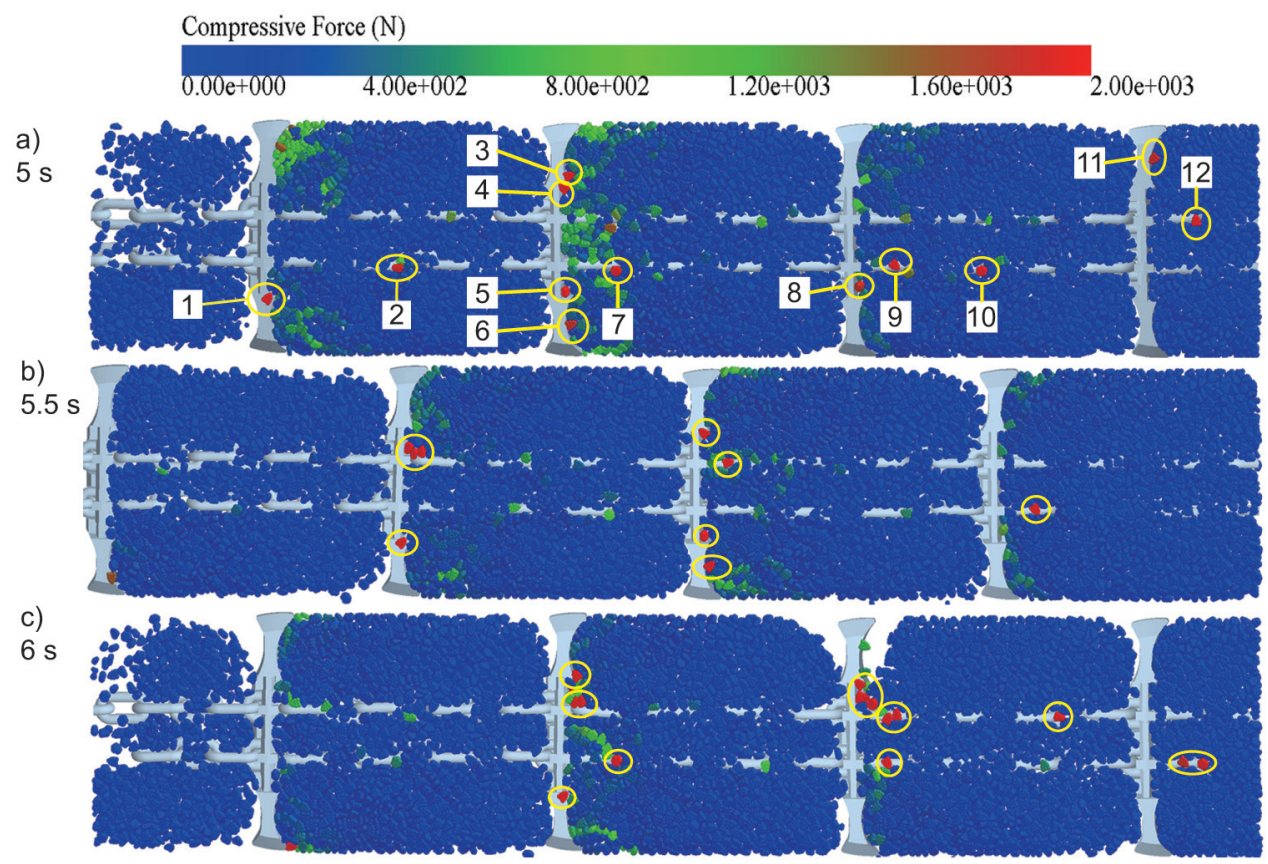

Fig. 10. Bulk compressive force cloud diagram; a) 5 s; b) $5.5 \mathrm{~s}$; and c) $6 \mathrm{~s}$ 
squeezed by scrapers or chainrings, which indicates that violent interaction happens. The cloud diagram seen from the chute bottom upward can clearly show coal particles squeezed by scrapers, chainrings, and chutes. The maximum value is set to $2000 \mathrm{~N}$, chutes and middle plates are hidden, and chains and scrapers are retained. The bulk coal compressive force cloud diagram of $5 \mathrm{~s}, 5.5 \mathrm{~s}$, and $6 \mathrm{~s}$ are drawn respectively, as shown in Fig. 10. The red particles circled in yellow indicate that these particles are squeezed. And the red particles are mainly located in two places: the bottom of scrapers and vertical chainrings, where the coal particles are squeezed between the scrapers, the chainrings and the middle plates. The compressive force value of 12 coal particles marked in yellow in Fig 10a is shown in Table 5. Ignoring the particle 1 and 4 that the force exceeds $10,000 \mathrm{~N}$, the average compressive force of the rest 10 particles is $3,536 \mathrm{~N}$. However, the average compressive force of all coal particles in the whole chute is only $59 \mathrm{~N}$ at $5 \mathrm{~s}$, and the average compressive force of the 10 particles is 59 times as much as that of all particles in the chute.

Draw the position relation diagram of extreme compressive force coal particles with scrapers, chainrings and middle plates at $5 \mathrm{~s}$, as shown in Fig. 11. The local enlarged picture of the corresponding particles below is shown above in the figure. The particles $1,3,5$, and 7 are squeezed between scrapers and middle plates; the remaining particles are squeezed between vertical rings and middle plates, which are almost all squeezed at the bottom of the front halfring of the vertical rings. Most of the scrapers and chainrings in the picture do not contact with middle plates, except for a few chainrings on the left. The left chainrings that just enter the chute are less affected by bulk coal, while the remaining chainrings and scrapers fully interact with the bulk coal and leave the middle plates, which makes the particles easy to squeeze.

The severe squeezing of scrapers, chainrings and middle plates with coal particles will affect the movement of scrapers and chainrings, but more importantly, it will cause serious wear of middle plates. Studies and practices have shown that the middle plate under two chains formed grooves due to wear, and the wear was significantly greater than other parts of the middle plate [20]. The above analysis reveals the causes of wear, which can be used to improve the shape of chainrings or other measures to reduce the possibility of coal particles being squeezed, so as to reduce the wear of the middle plate.

\subsection{The Clamping Condition of Scrapers}

Observing the movement of scrapers in the middle trough, a scraper (marked as scraper I) operates abnormally at $4.4 \mathrm{~s}$ and $5.9 \mathrm{~s}$ that one side of the scraper suddenly stop and the other side still advance; then, the scraper returns to normal operation. Both times, the scraper is located at the connection of two chutes. Scraper I is located at the connection of Chute 1 and Chute 2 at $4.4 \mathrm{~s}$, and is located at the connection of Chute 2 and Chute 3 at 5.9 s. Fig. 12 is the posture diagram of scraper I at these two moments, Figs. 12a and $\mathrm{c}$ shows the position relation of the stuck side of the scraper and the previous chute, Figs. 12b and $d$ are the bulk coal compressive force cloud diagram at these two moments seen from the chutes' bottom. The compressive force values are set in accordance with

Table 5. Compressive force value of 12 extreme particles at $5 \mathrm{~s}$

\begin{tabular}{|c|c|c|c|c|c|c|c|c|c|c|c|c|}
\hline Particle & 1 & 2 & 3 & 4 & 5 & 6 & 7 & 8 & 9 & 10 & 11 & 12 \\
\hline Force $[\mathrm{N}]$ & 103646 & 2855 & 2631 & 18524 & 5035 & 1835 & 7603 & 1841 & 4212 & 3867 & 1865 & 3614 \\
\hline
\end{tabular}
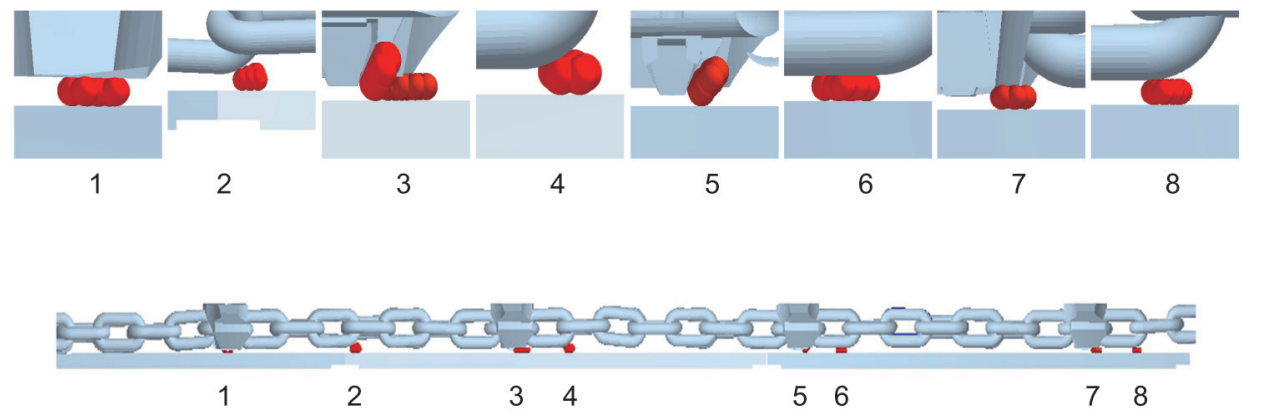

Fig. 11. The situation of extreme compressive force coal particles at $5 \mathrm{~s}$ 
Fig. 10, the chutes and the middle plates behind are hidden, and the middle plate previous is translucent. The part of the red circle in Fig. 12a shows the scraper is stuck at the top edge of the next chute at $4.4 \mathrm{~s}$, and the local enlarged picture shows the scraper is embedded in the chute. In Fig. 12b, the coal particles at the blocked end of the scraper are not subjected to extreme force, indicating that the scraper is not stuck on the chute through coal particles, but directly stuck on the chute. Figs. 12c and d are the position relation diagram of scraper I and chutes at $5.9 \mathrm{~s}$, which is similar to that at $4.4 \mathrm{~s}$ and will not be analysed in detail.

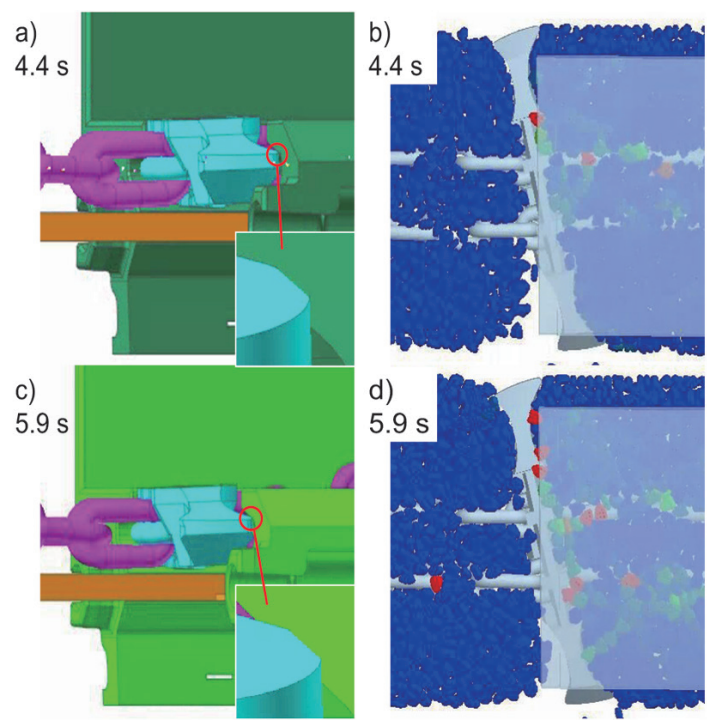

Fig. 12. The posture of scraper I at $4.4 \mathrm{~s}$ and $5.9 \mathrm{~s}$; a) the position relation of the scraper and chute at $4.4 \mathrm{~s}$; b) the bulk compressive force cloud diagram at $4.4 \mathrm{~s}$; c) the position relation at $5.9 \mathrm{~s}$; and d) the bulk compressive force cloud diagram at $5.9 \mathrm{~s}$

When the scraper is stuck in the chute, there is a huge contact force between the scraper and the chute, and the tension of the chain is affected. Fig. 13 shows the contact force in the y-direction between scraper I and chutes. The blue, red, and green lines respectively represent the contact force in the $\mathrm{Y}$ y-direction between scraper I and chute 1, 2 and 3, and the upper right corner is the local narrowing picture. At $3.5 \mathrm{~s}$ to $4.4 \mathrm{~s}$, the contact force in the y-direction is generated when Scraper I runs in Chute 1. During this period, Scraper I does not contact Chute 2 and 3, so both contact forces are 0 . Similarly, the contact force is generated between Scraper I and Chute 2 at $4.4 \mathrm{~s}$ to $5.9 \mathrm{~s}$, and between Scraper I and Chute 3 at $5.9 \mathrm{~s}$ to $6 \mathrm{~s}$. The contact force changes abruptly at about 4.4 $\mathrm{s}$ and about $5.9 \mathrm{~s}$, reaching the maximum $107 \mathrm{kN}$ and $113 \mathrm{kN}$, respectively, while the contact force in normal operation is around $5 \mathrm{kN}$. Fig. 14 shows the tension curves of the chainrings connected to the front and back of Scraper I. The upper right corner is the local narrowing picture. Around $4.4 \mathrm{~s}$ and $5.9 \mathrm{~s}$, the chain tension before the scraper increases to $302 \mathrm{kN}$ and $346 \mathrm{kN}$, respectively, while the maximum chain tension only reaches $80 \mathrm{kN}$ in other times, and the chain tension after the scraper turns to 0 around these time points, because the contact between the chainring and the scraper is loosened. When Scraper I is stuck, the chainrings before the scraper are subjected to the maximum force, and the maximum tension of chain rings are 2.8 and 3.1 times of the maximum contact force between the scraper and the chute, respectively.

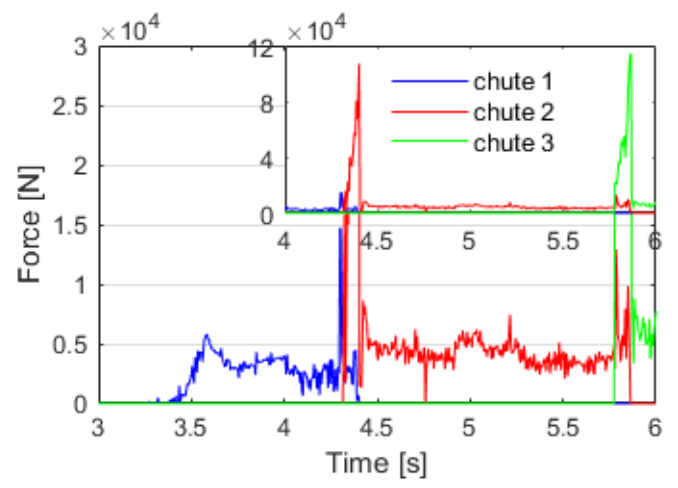

Fig. 13. The contact force in the $y$-direction between scraper I and chutes

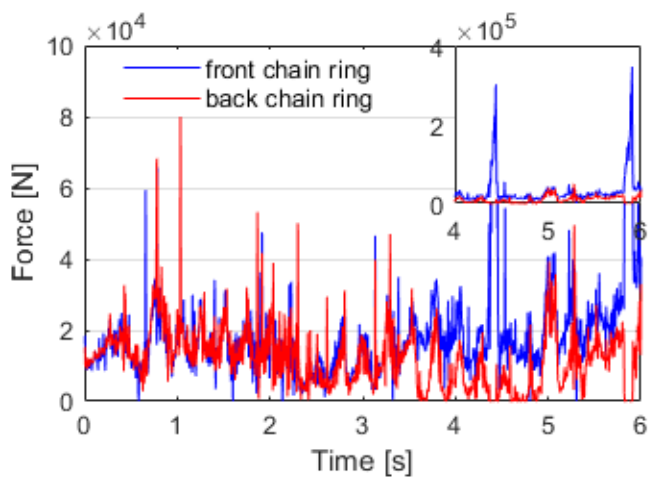

Fig. 14. The tension of the chains connected to the front and back of scraper I

The structural strength of chainring is smaller than that of scraper and chute, and the force on the chainring is larger than that of the scraper and chute, so the chain is more vulnerable to damage, and the frequency of chain-breaking accidents is higher in reality. The structure of the connection of two chutes should be optimized so that the scraper passes smoothly under the action of bulk coal. At the same time, the structural strength of chainring 
is strengthened to reduce the damage caused by the clamping.

\section{CONCLUSIONS}

The main conclusions of this paper are as follows:

(1) The rigid and discrete coupling model of scraper conveyor is established. The bulk coal force simulated by the discrete model reaches $87 \%$ of the test value, and the correlation coefficient $R$ between the simulation value and the test value of the bulk coal fluidity is close to 0.9879 . The coupling model can simulate the transport process of coal bulk in the middle trough, providing a new reference for the relevant research of scraper conveyor.

(2) The bulk coal compressive force distribution in the middle trough has an obvious gradient. The bulk coal compressive force in the chute is larger than that above chute. In the chute between two scrapers, in the y-direction, the bulk compressive force in the first half is about $19 \%$ of that in the second half, and in the $\mathrm{x}$-direction, the bulk compressive force between two chains is about $72 \%$ of that between the chain and the chute side.

(3) Coal particles are easily squeezed between scrapers and middle plates, and between vertical rings and middle plates. The average compressive force of the squeezed coal particles is $3536 \mathrm{~N}$, and the average force of all particles in chutes is $59 \mathrm{~N}$. The average compressive force of the squeezed coal particles is 59 times of that in chutes. Coal particles with extreme compressive force will aggravate the wear of the middle plate and affect the normal movement of scrapers and chainrings in the middle trough.

(4) The scraper is easily stuck at the connection of two chutes; especially at the top edge of the next chute. When it happens, the chainrings in front of the scraper will suffer the maximum tension, and the maximum tension of the chainrings is about three times that of the maximum contact force between the scraper and the chute.

Although the length of the model is short, the typical features of the chaindrive of the scraper conveyor are available. The conclusions above are worthy of reference for future research. Meanwhile, a complete scraper conveyor is more complex, and some mechanical characteristics are not reflected in this research.

\section{ACKNOWLEDGEMENTS}

This study was supported by National Natural Science Foundation of China (Grant Nos. 51804207 and 51875386); the merit funding for the returned overseas personnel sci-tech activities, Shanxi Province, China (Grant No.2016); Research Project Supported by Shanxi Scholarship Council of China (No.2016-43).

\section{REFERENCES}

[1] Broadfoot, A.R., Betz, R.E. (1995). Prediction of power requirements for a longwall armored face conveyor. IEEE Transactions on Industry Applications, vol. 33, no. 1, p. 80-89, Dol:10.1109/28.567081.

[2] Cenacewicz, K., Katunin, A. (2016). Modeling and simulation of longwall scraper conveyor considering operational faults. Studia Geotechnica et Mechanica, vol. 38, no. 2, p. 15-27, DOI:10.1515/sgem-2016-0015.

[3] Mao, J., Shi, J.G., Zhang, D.S., Wei, X.H. (2008). Dynamic modeling and simulation of heavy scraper conveyor. Journal of China Coal Society, vol. 33, no. 1, p. 103-106. (in Chinese)

[4] Cheluszka, P., Dolipski, M., Remiorz, E., Sobota, P. (2015). Follow-up chain tension in an armoured face conveyor. Archives of Mining Sciences, vol. 60, no. 1, p. 25-38, DOI:10.1515/amsc-2015-0002.

[5] Morley, L.A., Kohler, J.L., Smolnikar, H.M. (1988). A model for predicting motor load for an armored face-conveyor drive. IEEE Transactions on Industry Applications, vol. 24, no. 4, p. 649659, DOl:10.1109/28.6117.

[6] Szewerda, K., Świder, J., Herbuś, K. (2017). Analysis of impact of longitudinal inclination of a chain conveyor on dynamical phenomena during operation. MATEC Web of Conferences, vol. 94, art. 01010, D0l:10.1051/matecconf/20179401010.

[7] Ordin, A.A., Metel'kov, A.A. (2015). Analysis of longwall face output in screw-type cutter-loader-and-scraper conveyor system in underground mining of flat-lying coal beds. Journal of Mining Science, vol. 51, p. 1173-1179, D0l:10.1134/ s1062739115060452.

[8] Dolipski, M., Remiorz, E., Sobota, P. (2014). Dynamics of nonuniformity loads of afc drives. Archives of Mining Sciences, vol. 59, no. 1, p. 155-168, D0l:10.2478/amsc-2014-0011.

[9] Stoicuta, O., Pana, T., Mandrescu, C. (2016). The control system analysis of the coal flow on the scrapers conveyor in a longwall mining system. IEEE International Conference on Applied and Theoretical Electricity, p. 1-10, D0l:10.1109/ ICATE.2016.7754614.

[10] Dolipski, M., Remiorz, E., Sobota, P. (2012). Determination of dynamic loads of sprocket drum teeth and seats by means of a mathematical model of the longwall conveyor. Archives of Mining Sciences, vol. 57, no. 4, p. 1101-1119, Dol:10.2478/ v10267-012-0073-7.

[11] Jiang, S.B., Zhang, X., Gao, K.D., Gao, J., Wang, Q.Y., Hidenori, K. (2017). Multi-body dynamics and vibration analysis of chain assembly in armoured face conveyor. International Journal of Simulation Modelling, vol. 16, no. 3, p. 458-470, D0l:10.2507/ ijsimm16(3)8.391. 
[12] Kulinowski, P. (2014). Simulation method of designing and selecting tensioning systems for mining belt conveyors. Archives of Mining Sciences, vol. 59, no. 1, p. 123-138, DOI:10.2478/amsc-2014-0009.

[13] Wang, H., Zhang, Q., Xie, F. (2017). Dynamic tension test and intelligent coordinated control system of a heavy scraper conveyor. IET Science, Measurement \& Technology, vol. 11, no. 7, p. 871-877, D0I:10.1049/iet-smt.2016.0425.

[14] Broadfoot, A.R., Betz, R.E. (1998). Control problems in armored face conveyors for longwall mines. IEEE Transactions on Industry Applications, vol. 34, no. 2, p. 381-386, DOI:10.1109/28.663483.

[15] Lu, E., Li, W., Yang, X., Xu, S. (2018). Simulation study on speed control of permanent magnet direct-driven system for mining scraper conveyor. International Journal of Engineering Systems Modelling and Simulation, vol. 10, no. 1, p. 1-11, DOI:10.1504/ijesms.2018.10011292.

[16] Sobota, P. (2013). Determination of the friction work of a link chain interworking with a sprocket drum. Archives of Mining Sciences, vol. 58, no. 3, p. 805-822, D0I:10.2478/amsc-20130056.

[17] Thipprakmas, S. (2011). Improving wear resistance of sprocket parts using a fine-blanking process. Wear, vol. 271, no. 9-10, p. 2396-2401, D0l:10.1016/J.wear.2010.12.015.

[18] Wieczorek, A.N. (2013). Possibilities of increasing the durability of chain wheels of armoured-face conveyors. Transport Problems. vol. 12, no. 3, D0I:10.20858/tp.2017.12.3.7.

[19] Ge, S., Wang, Q., Wang, J. (2017). The impact wear-resistance enhancement mechanism of medium manganese steel and its applications in mining machines. Wear, vol. 376-377, p. 1097-1104, D0I:10.1016/j.wear.2017.01.015.

[20] Shi, Z., Zhu, Z. (2017). Case study: Wear analysis of the middle plate of a heavy-load scraper conveyor chute under a range of operating conditions. Wear, vol. 380-381, p. 36-41, D0l:10.1016/j.wear.2017.03.005.

[21] Krawczyk, J., Pawłowski, B. (2013). The analysis of the tribological properties of the armoured face conveyor chain race. Archives of Mining Sciences, vol. 58, no. 4, D0l:10.2478/ amsc-2013-0086.

[22] Cundall, P.A. (1971). A computer model for simulating progressive, large-scale movement in blocky rock system.
Proceedings of the International Symposium on Rock Mechanics.

[23] Cundall, P.A., Strack, O.D.L (1979). A discrete numerical model for granular assemblies. Geotechnique, vol. 29, no. 1, p. 47 65, DOI:10.1680/geot.1979.29.1.47.

[24] Wang, X., Li, B., Wang, S., Yang, Z., Cai, L. (2017). The transporting efficiency and mechanical behavior analysis of scraper conveyor. Proceedings of the Institution of Mechanical Engineers, Part C: Journal of Mechanical Engineering Science, vol. 232, no. 18, p. 3315-3324, DOl:10.1177/0954406217734002.

[25] Wang, X., Li, B., Yang, Z. (2018). Analysis of the bulk coal transport state of a scraper conveyor using the discrete element method. Strojniški vestnik - Journal of Mechanical Engineering, vol. 64, no. 1, p. 37-46, Dol:10.5545/svjme.2017.4790.

[26] Eberhard, P., Schiehlen, W. (2006). Computational dynamics of multibody systems: History, formalisms, and applications. Journal of Computational and Nonlinear Dynamics, vol. 1, no. 1, p. 3-12, Dol:10.1115/1.1961875.

[27] Huston, R.L. (1991). Multibody dynamics - modeling and analysis methods. Applied Mechanics Reviews, vol. 44, no. 3, p. 109-117, Dol:10.1115/1.3119496.

[28] Świder, J., Herbuś, K., Szewerda, K. (2017). Dynamic analysis of scraper conveyor operation with external loads. MATEC Web of Conferences, vol. 94, art. 01009, D0l:10.1051/ matecconf/20179401009.

[29] Hertz, H. (1880). On the contact of elastic solids. Journal für die Reine und Angewandte Mathematik, vol. 92.

[30] Mindlin, R., Deresiewicz, H. (1953). Elastic spheres in contact under varying oblique forces. Journal of Applied Mechanics, vol. 20, D0I:10.1007/978-1-4613-8865-4_35.

[31] Wang, G.Q., Hao, W.J., Wang, J.X. (2010). Discrete Element Method and Its Practice on EDEM. Northwestern Polytechnical University Press. Xian. (in Chinese)

[32] Li, T.J., Wang, X.W., Li, B., Li, J.L., Yang, Z.J. (2018). Optimization method for coal particle model parameters based on discrete element method. China Powder Science and Technology, vol. 24, no. 5, p. 6-12, D0l:10.13732/j. issn.1008-5548.2018.05.002. (in Chinese) 